Western University

Scholarship@Western

Aboriginal Policy Research Consortium International (APRCi)

2012

\title{
Indigenous Family Violence: An Attempt to Understand the Problems and Inform Appropriate and Effective Responses to Criminal Justice System Intervention
}

Andrew Day

Robin Jones

Martin Nakata

Dennis McDermott

Follow this and additional works at: https://ir.lib.uwo.ca/aprci

Part of the Other Mental and Social Health Commons

Citation of this paper:

Day, Andrew; Jones, Robin; Nakata, Martin; and McDermott, Dennis, "Indigenous Family Violence: An Attempt to Understand the Problems and Inform Appropriate and Effective Responses to Criminal Justice System Intervention" (2012). Aboriginal Policy Research Consortium International (APRCi). 378.

https://ir.lib.uwo.ca/aprci/378 
This article was downloaded by: [University of Western Ontario]

On: 18 July 2012, At: 10:47

Publisher: Routledge

Informa Ltd Registered in England and Wales Registered Number: 1072954 Registered

office: Mortimer House, 37-41 Mortimer Street, London W1T 3J H, UK

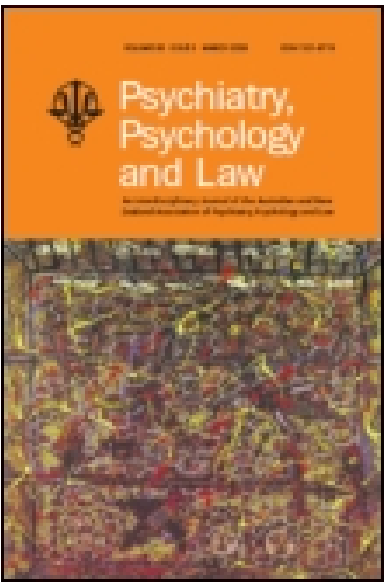

\title{
Psychiatry, Psychology and Law
}

Publication details, including instructions for authors and subscription information:

http:// www.tandfonline.com/loi/tppl20

\section{Indigenous Family Violence: An Attempt to Understand the Problems and Inform Appropriate and Effective Responses to Criminal J ustice System Intervention}

\author{
Andrew Day ${ }^{a}$, Robin J ones ${ }^{b}$, Martin Nakata ${ }^{c} \&$ Dennis \\ McDermott ${ }^{d}$ \\ a School of Psychology, Deakin University, Victoria \\ ${ }^{b}$ Melbourne University, Victoria \\ c J umbunna Indigenous House of Learning, University of \\ Technology, Sydney, New South Wales \\ ${ }^{d}$ Flinders University of South Australia, South Australia \\ Version of record first published: $01 \mathrm{~J}$ un 2011
}

To cite this article: Andrew Day, Robin J ones, Martin Nakata \& Dennis McDermott (2012): Indigenous Family Violence: An Attempt to Understand the Problems and Inform Appropriate and Effective Responses to Criminal J ustice System Intervention, Psychiatry, Psychology and Law, 19:1, 104-117

To link to this article: http:// dx.doi.org/ 10.1080/ 13218719.2010.543754

\section{PLEASE SCROLL DOWN FOR ARTICLE}

Full terms and conditions of use: http://www.tandfonline.com/page/terms-andconditions

This article may be used for research, teaching, and private study purposes. Any substantial or systematic reproduction, redistribution, reselling, Ioan, sub-licensing, systematic supply, or distribution in any form to anyone is expressly forbidden.

The publisher does not give any warranty express or implied or make any representation that the contents will be complete or accurate or up to date. The accuracy of any instructions, formulae, and drug doses should be independently verified with primary sources. The publisher shall not be liable for any loss, actions, claims, proceedings, 


\title{
Indigenous Family Violence: An Attempt to Understand the Problems and Inform Appropriate and Effective Responses to Criminal Justice System Intervention
}

\author{
Andrew Day ${ }^{\mathrm{a} *}$, Robin Jones ${ }^{\mathrm{b}}$, Martin Nakata ${ }^{\mathrm{c} *}$ and Dennis McDermott ${ }^{\mathrm{d}}$ \\ ${ }^{a}$ School of Psychology, Deakin University, Victoria; ${ }^{b}$ Melbourne University, Victoria; ${ }^{c}$ Jumbunna \\ Indigenous House of Learning, University of Technology, Sydney, New South Wales; ${ }^{d}$ Flinders \\ University of South Australia, South Australia
}

\begin{abstract}
Whilst high levels of concern about the prevalence of family violence within Indigenous communities have long been expressed, progress in the development of evidence-based intervention programs for known perpetrators has been slow. This review of the literature aims to provide a resource for practitioners who work in this area, and a framework from within which culturally specific violence prevention programs can be developed and delivered. It is suggested that effective responses to Indigenous family violence need to be informed by culturally informed models of violence, and that significant work is needed to develop interventions that successfully manage the risk of perpetrators of family violence committing further offences.
\end{abstract}

Key words: family violence; Indigenous; rehabilitation.

\section{Introduction}

Family violence is widely recognised as a major social problem around the western world, with international surveys suggesting that around one third of all adult women will experience abuse perpetrated by an intimate male at some point in their life. Nearly half of all incidents of domestic violence involve physical injury, and approximately two thirds of all women who are murdered in Australia are killed by their husband or live-in partner (Davies \& Mouzos, 2007). Given that domestic violence is rarely an isolated event and that known perpetrators often repeatedly offend (Gondolf, 2007), the logic underpinning calls to develop effective community responses to meet the needs of both victims and perpetrators is compelling.
The issue of family violence in Aboriginal communities is one which has, in recent years, received a lot of public attention. For instance, the Western Australian Inquiry into Response by Government Agencies to Complaints of Family Violence and Child Abuse in Aboriginal Communities (Gordon, Hallahan, \& Henry, 2002 p. xxiii) concluded that "the statistics paint a frightening picture of what could only be termed an 'epidemic' of family violence and child abuse in Aboriginal communities", and yet there have relatively been few attempts to articulate what such commentaries and analyses mean for those practitioners who work with perpetrators of violence. This is despite the release of rather significant levels of Commonwealth funding (e.g., through the Family Violence Partnership Program) to address issues relating to family violence and child abuse. In this article

Correspondence: Andrew Day, School of Psychology, Deakin University, Waterfront Campus, Geelong, Victoria 3127. Email: andrew.day@deakin.edu.au 
we seek to discuss some ideas with the potential to inform the development of interventions for perpetrators of family violence who identify as from Indigenous cultural backgrounds. Our aim in writing this review, however, is not to prescribe practice. Rather, it is to present some general perspectives and analyses which we believe can form the theoretical basis for effective intervention in this area. We acknowledge the need to develop programs and services that are tailored to the community in which they are to be used. In addition, there is a real danger, in any general review of this type, of stereotyping Indigenous offenders - and from the outset we acknowledge the considerable heterogeneity that exists in Indigenous communities and note that the term Indigenous in Australia is commonly used to refer to both Aboriginal and Torres Strait Islander peoples, groups which comprise more than 600 different cultures and tribal groups (Raphael, Swan, \& Martinek, 1998). It is apparent to us that the ways in which family violence is displayed will vary considerably across both different groups and contexts. Nonetheless, the extent of the problem and harmful effects of family violence demand that both criminal justice and mental health professionals work closely with Indigenous communities to develop meaningful and successful interventions. We hope that this article can make a meaningful contribution to such endeavours.

\section{Definitions of Family Violence}

The term "family violence" is used in this context to encapsulate both the extended nature of Indigenous families and the kinship relationships within which a range of forms of Indigenous violence frequently occur. Indigenous communities thus tend to prefer the term over the more widely used term "domestic violence", as it more accurately describes how violence reverberates through the entire family unit, and includes all victims of abuse, including spouses, children, and extended family members. Memmot, Stacy, Chambers, and Keys (2001) have suggested that family violence encapsulates: spouse assault, homicide, rape and sexual assault, child violence, suicide, self-injury, same-sex one-on-one adult fighting, inter-group violence, psychological abuse, economic abuse, cyclic violence, and what they refer to as "dysfunctional community syndrome". Family violence has thus been understood as focused around a wide range of physical, emotional, sexual, social, spiritual, cultural, psychological, and economic abuses that occur within families, intimate relationships, extended families, kinship networks, and communities (the Victorian Indigenous Family Violence Taskforce, 2003). It extends to one-onone fighting and abuse of Indigenous community workers, as well as self-harm, injury, and suicide.

These definitions tend to be far more inclusive than the definitions of violence that are commonly used by mental health and criminal justice professionals to classify offenders. They include behaviours that might otherwise be categorised as aggressive rather than violent. Howells, Daffern, and Day (2008), for example, have argued that the distinction between aggression and violence (defined by Blackburn, 1993, as the forceful infliction of physical injury), is largely based on the extent of physical harm inflicted. They suggest, following this distinction, that:

Clearly all acts of violence are aggressive, but not all acts of aggression are violent. Verbal insults would generally be viewed as aggressive rather than violent. Prolonged verbal abuse of a child by a parent, similarly, is probably best labelled as aggressive rather than violent in that the harm inflicted is predominantly psychological rather than physical in nature (p. 353). 
Howells and colleagues go on to argue that violent offending forms a sub-category of violence, referring specifically to acts of violence that contravene the legal code. Such definitional differences have potentially important implications for the assessment of offenders, and the circumstances in which interventions might be indicated, or even legally mandated.

\section{Patterns and Trends in Indigenous Violence}

The true extent of violence in Indigenous communities is difficult to determine due to under-reporting by victims, lack of appropriate screening by service providers, incomplete identification of Indigenous people in many data sets, and problems associated with the quality and comparability of existing data. There is often a reluctance to report offences for a number of reasons, including payback and fear of reprisal. In addition, it has been suggested that Aboriginal women sometimes feel compelled to protect men and themselves from further abuse at the hands of the criminal justice system. Lievore (2003) further notes that the problems in collecting reliable data are compounded by strained relationships between Indigenous and non-Indigenous peoples, and the lack of culturally appropriate support services and research methods. Consequently, the true prevalence rates are likely to be higher, and potentially much higher, than those reported in official statistics.

Violence in Indigenous communities and amongst Indigenous people is, however, usually considered to be disproportionately high, and has been identified as one of the major issues harming the fabric of Indigenous communities (Atkinson, 2002; Social Justice Report, 2002). Victorian prison data show that in $2004,46 \%$ of Indigenous offenders were incarcerated for robbery and offences against the person as their most serious offence (Department of
Justice, 2004). More recent figures (June 2007) have shown the same pattern, with $47 \%$ of Indigenous prisoners having current convictions involving violence. Furthermore, $41 \%$ of Koori men and $22 \%$ of Koori women had prior convictions including crimes against the person. In addition, NATSISS (2002) reported that one quarter $(25 \%)$ of Indigenous people surveyed had been a victim of physical or threatened violence (a figure that is nearly double the reported rate of 1994). Levels of victimisation were highest amongst young people aged $15-24$, with $36 \%$ of Indigenous young males and $30 \%$ of Indigenous young females reporting that they had been victimised.

\section{Frameworks for Understanding Indigenous Violence}

A great deal has been written in the Indigenous-focused literature to help make sense of these disproportionately high rates of violence. Much of this literature echoes some of the themes identified in other areas (e.g., the substance misuse treatment field), especially the material pertaining to the central role of colonisation and its aftermath in underpinning Indigenous violence. This is not repeated here, but is widely acknowledged to be important in understanding violence. For example, the Taskforce Report on Victorian Indigenous Family Violence (2003) identified five areas of contributing factors to family violence, based on their extensive community consultations:

(1) inherited grief and trauma;

(2) dispossession of land and loss of traditional language and cultural practices;

(3) loss of traditional Aboriginal roles and status (males and females);

(4) economic exclusion and entrenched poverty, including the impact of 
poor housing standards and overcrowding; and

(5) difficulties confronting the issues, for both victims and perpetrators.

Some additional, more proximal triggers for family violence were also identified. These included unemployment and financial stress; and frustration or feelings of low self-worth for men, arising from their "redundant" role, leading to violence against those around them. A particularly significant issue is alcohol. The Aboriginal and Torres Strait Islander Women's Task Force on Violence (1999) stated that "at every level, alcohol has been identified as a primary trigger for men acting violently" (p. 16).

Two related threads of thought can help to articulate the proposed connections between colonial history and present-day Indigenous family violence. Both were highlighted in the contributing factors identified in the Taskforce Report on Victorian Indigenous Family Violence (2003) and provide a useful basis from which to understand this issue.

\section{Indigenous Men's Role and Identity}

Many Indigenous researchers contend that the violent behaviour of some Indigenous men towards family members and kin is driven by a need to compensate for the sense of powerlessness that they experience in relation to the majority culture and their broader lives. For example, Aboriginal service providers interviewed in a study by Mals, Howells, Day, and Hall (1999) identified that male offenders, especially younger men in urban areas, suffered from low esteem and a pervasive sense of frustration, powerlessness, and anger. These men directed their anger and resentment not only towards mainstream society, but often also towards their parents, whom they saw as having failed them. They saw their emotional problems as arising directly from colonisation, disconnection from the land and a legacy of social and economic marginalisation. Similarly, Blagg (2005) has suggested that a key narrative of loss for Aboriginal men focuses on the "redundancy" of the Aboriginal male role and status, that is often compensated for by an aggressive assertion of male rights over women and children (see also Aboriginal and Torres Strait Islander Women's Taskforce on Violence, 1999; Blagg, 1999).

A related view, echoed in research and our review of program material around the country, is that government policies have often unintentionally reinforced the power differential between Indigenous women and men, in turn increasing men's feelings of inadequacy and the risk that they will release these feelings by perpetrating violence on women and children. The fact that women receive the child care benefit and baby bonus are two examples; also the recent welfare quarantining in the Northern Territory has more often put decisionmaking powers over money into the hands of women than men. It is paradoxical that while intended as forms of economic or social empowerment for women, the actual consequence for Indigenous women could sometimes be an increased risk of victimisation.

It is clear to most researchers and commentators working in this area that important aspects of Indigenous men's lives have been damaged through colonial processes, including cultural knowledge, education and employment prospects, the capacity to meaningfully support one's family members and kin, the ability to pass on of a legacy in which one takes pride, and the sense of positive agency and empowerment that accompany these things. Moreover, this is seen to affect behaviour in the present day in ways that actively perpetuate this disempowerment. These are some of the culture, gender specific processes that are potentially overlooked in violence intervention programs 
that have been developed from the perspective of the dominant culture.

\section{Connections between Intergenerational Trauma, Anger, and Indigenous Men's Violence}

A number of Indigenous researchers have further highlighted the role that grief/loss/ trauma plays in Indigenous family violence. Some of this work is purely theoretical in nature; some has been empirically investigated and supported through research, and all has been generated directly from consultations and narrative work with victims and/or perpetrators of violence against others or themselves. We have attempted to summarise some of the key hypotheses and/or findings arising from this body of research that relate specifically to Indigenous family violence.

Australian Indigenous practitioners Koolmatrie and Williams (2000) suggest that grief is by far the most intense, enduring, and distressing psychological disturbance experienced by Aboriginal people. They suggest that the grieving process can be expressed as both an individual and a group loss. In terms of intergenerational effects, Koolmatrie and Williams specifically identify anger as present:

I've spoken to people who say they've felt a real rage, going back in response to massacres and killings of their peoples. They've felt it inside of them and they say it has origins going back into the history of their families and peoples (p. 161).

Koolmatrie and Williams identify aspects of grief theory that may be relevant to understanding the Indigenous experience of grief - namely, of dependent grief, forbidden mourning, forbidden action, and inexpressible rage. Inexpressible rage is considered to be a particularly significant grief reaction for Indigenous men who engage in family violence. They describe inexpressible rage as follows:

Anger is a normal component of adjust-
ment to loss. Irrational anger at the
departed for abandoning those who
remain, at medical staff for failing to
save a life, at other survivors, at fate itself,
is normal. If a child is murdered, the
terrible, 'just anger' of the parents finds
relief in the state's determined efforts to
arrest and punish the culprit. But what
happens when the state itself is the
culprit? When 'just rage' is forbidden
from any expression? (p. 163).

The suggestion here, then, is that for some Indigenous men, intergenerational grief and loss is experienced as pervasive, generalised anger that is passed on to each generation on the basis of collective memories and experiences and which, fundamentally, has no legitimate outlet. Combining this internal experience with alcohol abuse and/or a series of other stressors such as financial woes, interpersonal conflict, or feelings of jealousy may create a direct pathway to the expression of anger towards family members, often disproportionate to the triggering event.

The theme of hidden, unacknowledged, or inexpressible anger as a part of Indigenous experiences of grief is also important in the work of Rosemary Wanganeen, whose theories incorporate the powerful intergenerational impacts of colonisation and associated loss and grief (Wanganeen, 2008). She makes a distinction between recognised and unrecognised loss, and contends that unrecognised losses cause more damage and perpetuation of trauma, and that uncovering them is an important aspect of healing. Wanganeen associates unrecognised loss with the "loss of identity, power, trust, faith, confidence and selfesteem", which again supports the idea that Indigenous people are dealing with pressures that may be pervasive and corrosive to their wellbeing. It is a short 
step from there to violence as an outlet for frustration and internalised or unprocessed pain, and may be directed at family members and kin because these are the persons with whom the greatest share of time - and day-to-day frustrations - is spent.

There is a small body of empirical research which supports these culturally specific conceptualisations of violence. For example, in a study of male and female substance abusers in Queensland, Atkinson (2002) reported that all had had severe histories of trauma and abuse, including being victims and/or perpetrators of family violence. As well as reinforcing the link between family violence and substance abuse, this study illustrated the complex links between experiencing trauma and reenacting it, either as a perpetrator or as a repeat victim. Many of Atkinson's findings are consistent with those of Koolmatrie and Williams (2000), for example, that anger is experienced as a natural and essential consequence with no safe outlet and as such is expressed under conditions of duress. This is described as impacting on the wellbeing of Aboriginal peoples, in terms of physical health and also in terms of actions towards self (e.g., self-harm) and others (e.g., violence).

Another study of Indigenous men's perceptions of anger has also helped to articulate some of the connections between past experience (including historical) and present violent behaviour. Interviews with Indigenous men both in prison and in the community described by Day, Nakata, and Howells (2008) identified four general triggers to anger and violence: anger at their own situation; anger at family and others; anger at historical treatment; and anger at perceived injustice. These general conditions appeared to "wrap around" the more immediate or specific triggers for anger reported by men, such as specific family problems; alcohol and other drugs; direct experiences of loss; and direct experiences of perceived discrimination. Contextual triggers were also identified by the men, and consistently fell into four categories:

(1) Growing up with disrupted family lives, defined as at least one (and often more) of the following experiences: removal from families, institutionalisation, foster care, juvenile detention, moving back and forth between institutions, foster care and/or families, living apart from siblings or one or both parents which resulted in intermittent, complicated, or unresolved, or ambivalent relationships between family members.

(2) Growing up experiencing or witnessing anger and/or violence, and being exposed to pervasive and sustained historical and contemporary anger across individuals, families, and communities. The men described a sense of being surrounded by anger and violence in institutions, families, and communities, within and beyond their own generation. They tended to respond with anger and violence almost automatically to other people's behaviour, external events, or perceived provocation, and had little access to other ways of dealing with it. Avoiding the conditions or stressors that trigger their anger and violence would appear to be almost impossible for most men in their daily lives.

(3) Drug and alcohol abuse: Using alcohol appeared to be associated with blocking out pain, coping with life, and socialising. Its disinhibiting effects were seen as providing an outlet or a form of release through violence, including deliberately inciting violence as a form of selfharm. Giving up alcohol and/or 
drugs appeared to be a condition of managing anger more appropriately.

(4) Impacts of government policy/intervention and racism/discrimination - historical and ongoing: The Indigenous men who participated in this study reported feelings of powerlessness on a daily basis, and a range of associated emotions leading to anger and violence, including frustration, being overwhelmed, being trapped, feeling threatened, feeling intimidated, loss of control, and fear of loss of control. There was recognition that their capacity to act in their own interests has historically been subject to quite oppressive constraints, and their resulting socio-political powerlessness was seen to have had very real effects on their social and emotional wellbeing.

\section{Implications for Practice}

There are a number of systemic and organisational issues that potentially influence what might be considered to be the appropriate goals of any intervention. It could be argued, for example, that a systemic perspective entails seeing the client's participation in a group-based perpetrator program as one part of a broader strategy to monitor risk and support victims and holding perpetrators accountable, rather aiming to rehabilitate or "treat" the individual offender. From this perspective, the system is the focus of analysis rather than the individual client. Thus, the primary goal of the intervention is more general, and focuses on the development of inter-agency protocols and responsibilities that will afford continuing victim protection and formal integration of domestic violence services related to the victim, criminal justice, and other related social service agencies. This is closely related to issues of legally enforced intervention, and is consistent with an approach to intervention as a structural and political strategy involving the socially sanctioned use of power. It also highlights the needs for perpetrator program providers to be mindful at all times of the ongoing risks to women and other family members, and of their overarching responsibility to manage and report this.

In many ways the focus on victim issues (i.e., women's safety) in most contemporary domestic violence programs can be considered to be a defining feature of this type of work. In addition to the therapeutic contact occurring because of the past harm caused to a victim, program facilitators are obliged to closely monitor the ongoing and future risk of further harm, mainly because the context in which the original offence took place is often largely unchanged when a perpetrator enters a program. Attending closely to the needs of victims is also likely to influence therapeutic practice - the practitioner's level of awareness of the harms caused by an individual client will influence the way that he or she relates to him (or her), and will set the tone for the sessions that follow. In relation to sentencing, some have suggested that victim involvement can lead to vengeful and disproportionate punishments, which is perhaps one reason why the conventional criminal justice system continues to place victim's rights on the periphery of justice proceedings (Ward \& Langlands, 2009).

One of the major therapeutic tasks in violence perpetrator programs is reaching a shared understanding with each client about the nature, extent, and seriousness of the violence. Family violence differs from other types of violent offending in so far as offending may occur behind closed doors, where the only witnesses are victims. As a result, the facts of the offence are often difficult to establish, and male perpetrators commonly dispute the evidence that is presented to the police or 
the courts in relation to the frequency and intensity of their violence, the reliability of the victim statements, and on a basic level the extent to which they consider themselves to be personally responsible. Indeed, men typically arrive in programs believing that their behaviour was justified, that their violence was appropriate, and even that it would have been inappropriate for them to have acted in any other way. To borrow the phrase of Howells (1998), their behaviour is "ego-syntonic". Furthermore, given that angry and aggressive behaviour can lead to social perceptions of status, strength, and competence (Tiedens, 2001), any attempt to induce change is likely to elicit ambivalent reactions in the client and greater treatment resistance.

Given that many clients may not, at least in the early stagesof intervention, have personal goals that are consistent with program goals (i.e., women's safety), or have goals that are incompatible with program goals (e.g., to fulfil the obligations of the order; to change the partner's behaviour; to punish the family member, etc.), it is perhaps unsurprising that facilitators commonly find difficulties in engaging clients in a change process, and often report encountering hostility, resistance, and difficulties in engaging men in therapeutic change. One particular difficulty in the domestic violence field is that of very high attrition rates from programs, typically between $50 \%$ and $75 \%$ (Buttell \& Carney, 2008). Gondolf (2008), for example, reported a completion rate of approximately $55 \%$ for a 16 -week group-based program. Such statistics are of major concern given the evidence those who start, but who do not complete rehabilitation programs, are left at higher risk of re-offending that those who do not enter programs at all (see McMurran \& Theodosi, 2007).

These considerations suggest that it is essential for thoseinvolved in program delivery to have the cultural skills to firstly understand the context in which violence occurs in Indigenous families, and secondly work in ways that maximise the chances of therapeutic engagement. Mainstream programs are commonly considered to be culturally unsafe and, in the words of one respondent interviewed by Mals et al. (1999), "Aboriginal offenders simply vote with their feet", and do not attend sessions unless under a high degree of coercion. The process of confrontation and the underlying assumption that the client must be "jolted" into active behaviour change in order to overcome claims that the behaviour was not serious, or that their victims provoked or deserved the violence (Dutton, 1986; Pence \& Paymar, 1983), is a critical part of interventions for perpetrators of violence requiring the facilitator to persuade, cajole, and motivate offenders into some form of agreement with the basic goal of non-violence (Levesque, Velicer, Castle, \& Greene, 2008; Murphy \& Baxter, 1997). It is easy to imagine how highly confrontational approaches delivered by culturally incompetent facilitators can alienate Indigenous participants.

In one of the few explorations of the issue of who should facilitate programs, Mals et al. (1999) reported that there was a general consensus that Indigenous facilitators would have a strong advantage in their ability to establish rapport. Respondents suggested that non-Indigenous workers would be regarded initially with suspicion, if not outright distrust and hostility, and/or that participants might be reluctant to talk about their circumstances and way of life, out of fear that they will be "looked down on". In addition to considerations of rapport, it was suggested that Indigenous facilitators would also have a better sense of how program content might need to be modified for delivery. Some had found that there were certain concepts which seemed alien and incomprehensible to Indigenous participants. In some instances, the difficulties in comprehension had remained 
despite facilitators' best efforts at explanation, thus leaving them with the impression that the problem was cultural in nature, rather than merely one of vocabulary.

Overall, however, the prevailing view presented by Mals et al. (1999) was that the difficulties faced by non-Indigenous facilitators were substantial, but by no means insurmountable. The great majority of the sample believed that nonIndigenous workers could develop the capacity to relate to and work effectively with this client group. Respondents also acknowledged the potential difficulties which family connections might pose for Indigenous workers.

The issue of culturally appropriate staffing of programs for Indigenous offenders is repeatedly raised in the literature we reviewed. Although it is widely accepted to be an important aspect of good practice, serious limitations have been identified in offender programs, particularly in relation to difficulties in recruiting and maintaining Indigenous staff, and insufficient staff expertise and support (e.g., Gray, Saggers, Sputore, \& Bourbon, 2000). Appropriate forms of training and support for Indigenous and non-Indigenous staff in Indigenous have been identified, perhaps more frequently than they have been applied.

Difficulty in recruiting Indigenous staff is a major barrier to full Indigenous involvement in the planning, facilitation, and evaluation of offender rehabilitation programs. Many researchers have linked this to Indigenous mistrust and ambivalence towards the mainstream criminal justice system (e.g., Cunneen, 2008), and some Indigenous people who choose to work in correctional settings face strong criticism from members of their families or communities. Retaining Indigenous staff is also a concern. Burnout is a commonly cited reason for this, where a number of culture-specific considerations are also at work. For example, local research undertaken by the Koori Recruitment and Career Development Strategy in Victoria (Jones \& McCormick, 2007; Jones \& Stevens, 2004) identified important areas of work-related stress that were specific to Aboriginal Justice workers, and exist in addition to the regular day-to-day stresses of the job. These included having to constantly negotiate conflicts between their roles as public servants and their roles as community members; dealing with interpersonal and institutional racism that could take both overt and covert forms; and coping with high levels of personal stress arising from some of the same issues as the Koori prisoners are facing, since the workers are not immune from communitywide concerns. This could include family and lifestyle stressors and/or also vicarious trauma when dealing with the personal issues in offenders' lives. These findings highlight, at the local level, how important it is to take good care of the Indigenous staff who become involved in the planning, delivery, and/or evaluation of family violence programs. Some potential solutions identified in this review of literature from both mainstream and Indigenous sources are listed in Table 1.

A related issue is the development of non-Indigenous staff who may work alongside Indigenous workers, or in supervisory or managerial positions. There is a need for cultural awareness and competency training of non-Indigenous program staff, not only to ensure high-quality program delivery, but also to reduce the stress frequently experienced by Indigenous staff if their non-Indigenous colleagues lack these skills and knowledge.

Indigenous-focused research and training undertaken in Australia is helping to articulate the skills mainstream psychologists need if they are to work effectively with Indigenous people. Vicary and Bishop (2005), for example, have reported that in Western Australia non-Indigenous 
Table 1. Managing the needs of Indigenous family violence program practitioners.

Acknowledgement of cultural knowledge and connections as a qualification in addition to mainstream education.

Ensuring job descriptions and duty statements enable Indigenous staff to meet the needs of Indigenous offenders in a manner that satisfies the community as well as the government's expectations. This may mean, for example:

smaller caseloads to reflect the higher complexity of needs for many Indigenous offenders

flexibility about out-of-office work so effective community contacts can be made recognition for time spent upskilling non-Indigenous colleagues.

Regular training and development opportunities that are:

delivered by Indigenous as well as non-Indigenous trainers and are culturally appropriate - for example, respecting different ways of learning, and involving elders and respected persons in the design of staff training courses

directly relevant to the work the staff are undertaking - not generic or "one size fits all"

tailored to their specific professional development needs, including increasing their understanding of how mainstream systems and bureaucracies function

delivered in an active format that focuses on the best ways to transfer evidence-based knowledge into the practical and real issues that workers face

Regular supervision that combines accountability with support and skills development

Prevention and rapid resolution of conflicts or "politics" in the workplace. This may require support and action from senior personnel, for example to address subtle forms of racism

A variety of strategies to reduce Indigenous workers' isolation from each other in mainstream workplaces, such as formal and informal opportunities to network within and across business units or departments, culture-focused staff retreats or conferences

Culturally sensitive and appropriate mediation services, grievance processes, and counselling for staff experiencing workplace problems.

psychologists have worked closely with Aboriginal consultants and reference groups to develop a model of engagement for psychologists working with Aboriginal clients in community settings. McDermott (2007), a New South Wales Koori psychologist, has provided workshops for workers seeking to improve their skills in working with Indigenous people in health settings. While neither of these bodies of work have specifically targeted the criminal justice area, many of their suggestions are relevant nevertheless to the development of family violence programs (see Table 2).

Cultural awareness training is the most obvious strategy to address this area of need. However, we have encountered shortfalls in the quantity of such training required of non-Indigenous workers in many Australian government settings. Fixed-length, one-off training workshops are often all that is formally required prior to undertaking work with Indigenous clients or policy matters. Jones, Masters,
Griffiths, and Moulday (2002) and Mals et al. (1999) suggest a range of additional strategies to strengthen this approach. These have produced positive outcomes in other jurisdictions, most notably New Zealand, where Maori client satisfaction with non-Maori justice workers has improved. For example, regular, ongoing cultural awareness training for non-Indigenous staff that moves through McDemott's phases from cultural awareness to cultural competence to cultural safety in policy and practice. This is much more than the "oneoff" cultural awareness training routinely provided by most government departments; cultural oversight and advice to all project staff through Indigenous Reference Groups, Elders Councils, or other Indigenous bodies. This can include active solicitation of culture-specific feedback on all program elements; and regular cultural supervision for non-Indigenous workers by cultural experts and informants to assist with matters of everyday practice. 
Table 2. Managing the needs of non-Indigenous family violence program practitioners.

Vicary and Bishop (2005) suggest the following three steps be undertaken before non-Indigenous psychologists undertake assessment and therapy with Aboriginal clients:

Self-reflection: about their motives for wanting to work with Aboriginal people

Formative preparation: undertake cultural awareness training, develop links with cultural consultants, review their microcounselling skills

Networking and supervision: build relationships with Aboriginal colleagues, organisations and communities; establish professional and cultural supervision mechanisms.

McDermott (2007) has highlighted the need for non-Indigenous workers to develop the following skills and strategies:

Understanding of local Aboriginal community issues, cultural protocols, and histories - being "clued in"

Skills in deep listening

Commitment to relationships and "the long haul" with Aboriginal clients and community

Reducing the power distance - "taking off the professional hat"

Working closely with Indigenous colleagues and other cultural informants

Actively working towards system change to incorporate Indigenous values, principles, and ways of doing business.

Regular opportunities also exist for a two-way exchange of information and skills transfer between Indigenous and non-Indigenous front-line workers. NonIndigenous staff, for example, can assist Indigenous staff with navigating the mainstream bureaucracy, while Indigenous staff can assist their non-Indigenous counterparts with face-to-face work with offenders, and developing relationships with Indigenous community leaders and organisations. Finally, Maori researchers (e.g., McFarlane-Nathan, 1999) have also pointed out the importance of ensuring that Indigenous staff can access cultural awareness training. In exploring the impacts of deculturation for Indigenous workers, they identify a hidden source of job stress as the implied expectation that Indigenous workers will hold the cultural knowledge to deal with all Indigenous matters, will forge all necessary Indigenous service connections, and will act as spokespersons for their entire community. This is unrealistic, and when the corrosive effect of deculturation over the past few generations is also taken into account, it becomes clear that many Indigenous workers will also benefit from ongoing cultural competency and cultural safety training by their peers and elders. This does not undermine but rather strengthens the cultural knowledge they already bring to Indigenous-focused offender rehabilitation programs.

A number of other observations were made by Mals et al. (1999) from their interviews with Indigenous service providers. Perhaps unsurprisingly, they described a strong body of opinion that prison-based programs would not be effective by themselves, divorced from the broader community. It was noted, for example, that in the typical family violence situation other members of the family would be directly involved and might therefore play key roles in the perpetuation or resolution of the conflict. In addition, a number of informants raised the issue of whether those from urban and remote areas should be mixed. It was argued that in working with traditional men there were cultural issues of considerable complexity which needed to be handled in a sensitive and well-informed way; whereas the problems of urban offenders could be dealt with in much the same way as those of nonIndigenous offenders. Another important issue highlighted by informants was the nature of the pre-existing relationships between individuals within the group. ${ }^{1}$ Finally, opinion amongst service providers was divided as to whether (anger 
Table 3. Recommendations for female perpetrator programs.

Provide women's programs that are more intensive than men's, due to the greater level and complexity of needs experienced by women offenders. Due to the comparatively shorter sentences received by women, this may call for programs that are intensively blocked over relatively short periods of time, rather than less intensive over periods of many months.

Ensure violence intervention and substance misuse programs include a very strong trauma and loss (and recovery) component, because victimisation is such a prevalent and severe underlying factor for women offenders.

As for the men, balance victimisation issues with personal responsibility issues in programs for women.

Pay particular attention in women's programs to connections between women's violence and/or substance misuse and (i) mental health concerns and (ii) enmeshment in violent intimate relationships.

Ensure women's programs recognise and respect women's obligations to community, while at the same time promoting family and child safety and wellbeing.

Ensure that women's programs, if based on a feminist philosophy, have been sufficiently adapted and transformed by Indigenous people so they reflect Indigenous rather than mainstream interpretations of feminism, especially in relation to structural explanations for men's violence.

Ensure women's programs provide very intensive, culturally appropriate transition and post-release support, since risks of relapse, recidivism, and death in the immediate post-release period are especially acute for Indigenous women.

management rather than family violence) groups should be racially segregated or mixed. The principal argument in favour of segregation was that it would facilitate selfdisclosure on the part of Indigenous men. ${ }^{2}$ Some informants reported that when Indigenous men formed a small minority within a mixed treatment group they had tended to remain passive and withdrawn. Segregation, it was felt, would also allow for better targeting of treatment on issues of particular relevance. An opposing argument was that segregation might lead some to feel as if they were being singled out by the system as being particularly violent or out-of-control, and that it could be therapeutic for an Indigenous man to be able to see the communalities between his problems and those of non-Indigenous offenders.

\section{Programs for Female Perpetrators}

An important theme in the Indigenous perspective is that some aspects of the role of Indigenous women have been similarly damaged, while other aspects have not. Colonisation, it is suggested, did not impinge upon women's biological role as the bearers of children and, therefore, women have been able to maintain this part of their identity as women. Colonisation did, however, impinge on their ability to raise their children, through forced removals. Grief and loss issues for Indigenous women may therefore resonate especially strongly in relation to child removal policies, loss of functionality of extended family, parenting and communal child-rearing structures, along with witnessing and bearing the brunt of the gradual disintegration of the wellbeing of their men. For Indigenous women who are victims of family violence - and for Indigenous female perpetrators too - this perspective adds some unique dynamics into their experience which simply do not exist for non-Indigenous women, and are therefore not reflected in mainstream feminist theories. The following recommendations have been made in relation to the provision of programs for women (Table 3).

\section{Conclusion}

What emerges from the review is the idea that personal histories and broader sociopolitical histories cannot, and should not, 
be separated; indeed it is, in our view, only by virtue of the interconnections between these two levels of experience that indigenous family violence can be appreciated and understood. It is also evident to us that effective programs cannot be developed and delivered without the active and central participation of members of the Indigenous community.

Cultural knowledge is a prerequisite for effective program delivery, and there are substantial barriers facing non-Indigenous practitioners who attempt to work in isolation from the support of their local community. Notwithstanding these issues, significant progress has been made in relation to the successful management and treatment of violent individuals (see Howells, Daffern, \& Day, 2008) and this (largely Western cultural) knowledge should be utilised in interventions for Indigenous participants. The conclusion from this review is that more work is required to operationalise these ideas into meaningful programs for Indigenous offenders, and evaluate their impact upon behaviour and community safety. However, there are some grounds for optimism that properly designed and culturally safe programs for offenders can have a meaningful impact on the safety of Indigenous families and the communities in which they live.

\section{Notes}

1. Three types of difficulty were identified as being more likely to arise amongst Aboriginal participants than non-Aboriginals. Firstly, in any given locality, there would be a substantial risk that an offender will encounter, in the treatment group, someone who has family connections with the victim of his crime. Self-disclosure in this context would be impeded not only by a sense of shame but also fear of "payback." Secondly, there is the possibility that two members of the group might be from opposing sides of a family feud (which might have nothing to do with the offences which brought either of them into prison). Thirdly, where more traditional people are concerned, two members of the treatment group may be in a kinship connection which prohibits their speaking to each other (i.e. an avoidance relationship).

2. It was felt that all members of the group would have a common cultural and socioeconomic background, would therefore feel more comfortable and be more likely to be open with each other.

\section{References}

Aboriginal and, Torres Strait Islander Commission. (1999). Women's Task Force on Violence Report. DATSIPD, Brisbane.

Atkinson, J. (2002). Trauma trails: Recreating song lines. Melbourne: Spinifex.

Blackburn, R. (1993). The psychology of criminal conduct. Chichester: Wiley.

Blagg, H. (1999). Aboriginal family violence: Prevention and crisis intervention. In $\mathrm{R}$. Thomson (Ed.), Working in indigenous perpetrator programs: Proceedings of a forum (pp. 152-175). Darwin, NT: Ministerial Council for Aboriginal and Torres Strait Islander Affairs.

Blagg, H. (2005). A new way of doing justice business? Community justice mechanisms and sustainable governance in Western Australia. Law Reform Commission of Western Australia, State Solicitor's Office. Background Paper No. 8.

Buttell, F.P., \& Carney, M.M. (2008). A large sample investigation of batterer intervention program attrition: Evaluating the impact of state program standards. Research on Social Work Practice, 18, 177-188.

Cunneen, C. (2008). Indigenous anger and the criminogenic effects of the criminal justice system. In A. Day, M. Nakata, \& K. Howells (Eds.), Indigenous men and anger: Understanding and responding to violence (pp. 3746). Annadale, NSW: Federation Press.

Davies, M., \& Mouzos, J. (2007). Homicide in Australia: 2005-06 national homicide monitoring program annual report. Canberra: Australian Institute of Criminology.

Day, A., Nakata, M., \& Howells, K. (2008). Indigenous men and anger: Understanding and responding to violence. Annandale, NSW: Federation Press.

Dutton, D.G. (1986). The outcome of courtmandated treatment for wife assault: A quasi-experimental evaluation. Violence and Victims, 1, 163-175.

Gondolf, E.W. (2007). Theoretical and research support for the Duluth model: A reply to Dutton and Corvo. Aggression and Violent Behavior, 12, 644-657. 
Gondolf, E.W. (2008). Program completion in a specialized batterer counseling for AfricanAmerican men. Journal of Interpersonal Violence, 23, 94-116.

Gordon, S., Hallahan, K., \& Henry, D. (2002). Putting the picture together: Inquiry into response by government agencies to complaints of family violence and child abuse in aboriginal communities. Western Australia: Department of Premier and Cabinet.

Gray, D., Saggers, S., Sputore, B., \& Bourbon, D. (2000). What works? A review of evaluated alcohol misuse interventions among Aboriginal Australians. Addiction, 95, 11-22.

Howells, K. (1998). Cognitive behavioural interventions for anger, aggression and violence. In N. Tarrier, A. Wells, \& G. Haddock (Eds.), Treating complex cases (pp. 295-318). New York: John Wiley \& Sons.

Howells, K., Daffern, M., \& Day, A. (2008). Aggression and violence. In K. Soothill, M. Dolan, \& P. Rogers (Eds.), The handbook of forensic mental health (pp. 351-374). Cullompton, Devon: Willan.

Jones R.L., Masters, M., Griffiths, A., \& Moulday, N. (2002). Culturally relevant assessment of Indigenous offenders: A literature review. Australian Psychologist, 37(3), 187-197.

Jones, R.L., \& McCormick, T. (2007). Looking after ourselves and each other: An Indigenous-focused burnout prevention workshop. Koori Justice Network Conference, Hepburn Springs, Victoria.

Jones, R.L., \& Stevens, M. (2004). Koori staff burnout prevention survey and workshops. Koori Justice Network Conference, Cape Schank, Victoria.

Koolmatrie, J., \& Williams, R. (2000). Unresolved grief and the removal of Indigenous children. Australian Psychologist, 35, 158-166.

Levesque, D.A., Velicer, W.F., Castle, P.H., \& Green, R.N. (2008). Resistance among domestic violence offenders. Violence against Women, 14, 158-184.

Mals, P., Howells, K., Day, A., \& Hall, G. (1999). Adapting violence programs for the Aboriginal offender. Journal of Offender Rehabilitation, 30(1-2), 121-135.

McDermott, D. (2007, July). What cure for Tamworth Syndrome? The accumulative experience of racism, blackfella well-being and psychological practice. Cultural Competence \& Psychology Workshop, University of South Australia, Adelaide.
McFarlane-Nathan, G. (1999). FreMO: Framework for reducing Maori offending. Wellington, New Zealand: Department of Corrections.

McMurran, M., \& Theodosi, E. (2007). Is treatment non-completion associated with increased reconviction over no treatment? Psychology, Crime and Law, 13, 333-343.

Memmot, P., Stacy, R., Chambers, C., \& Keys, C. (2001). Violence in Indigenous communities. National Crime Prevention Program, Canberra.

Murphy, C.M., \& Baxter, V.A. (1997). Motivating batterers to change in the treatment context. Journal of Interpersonal Violence, 12, 607-620.

Pence, E., \& Paymar, M. (1983). Education groups for men who batter: The Duluth Model. New York: Springer.

Raphael, B., Swan, P., \& Martinek, N. (1998). Intergenerational aspects of trauma for Australian Aboriginal people. In Y. Danieli (Ed.), International handbook of multigenerational legacies of trauma (pp. 327-339). New York: Plenum.

Social Justice Report.. (2002). Aboriginal and Torres Strait Islander Social Justice Commisioner. Human Rights and Equal Opportunities Commission, Canberra.

Tiedens, L.Z. (2001). Anger and advancement versus sadness and subjugation: The effect of negative emotion on social status conferral. Journal of Personality and Social Psychology, 80, 86-94.

Vicary, D.A., \& Bishop, B.J. (2005). Western psychotherapeutic practice: Engaging Aboriginal people in culturally appropriate and respectful ways. Australian Psychologist, 40, 8 19.

Victorian Indigenous Family Violence Task Force Final Report. (2003). Aboriginal Affairs Victoria, Department for Victorian Communities.

Wanganeen, R. (2008). Grief and loss. In A. Day, M. Nakata, \& K. Howells (Eds.), Indigenous men and anger: Understanding and responding to violence (pp. 73-86). Annandale NSW: Federation Press.

Ward, T., \& Langlands, R. (2009). Repairing the ruptures: Restorative justice and the rehabilitation of offenders. Aggression and Violent Behavior, 14, 205-214. 